\title{
A GESTÃo DEMOCRÁTICA DA ESCOLA PÚBLICA SOB A ÉGIDE DO CAPITALISMO NEOLIBERAL
}

\author{
Clarice Zientarski ${ }^{1}$
}

\section{Resumo}

O trabalho tem como objetivo discutir as contradições que estão postas para a gestão democrática da escola pública no contexto capitalista neoliberal, considerando que a legislação estabelece este princípio na C. F de 1988, na LDB n ${ }^{\circ}$ 9.394/96 e no PNE 2014/2024- Lei $n^{0}$ 13.005/2014. Nesse prisma, parte da premissa de que estão assegurados progressivos graus de autonomia pedagógica, administrativa e de gestão financeira, observada às normas gerais de direito financeiro público aos profissionais da educação, comunidade educativa e unidades de ensino. Trata-se de uma pesquisa bibliográfica e documental com abordagem qualitativa, situando-se como um dos estudos realizados pelo Grupo GEPPGE/UFC. O desenvolvimento das investigações, embora parciais, tendo em vista a continuidade das aferições, leva a concluir que a gestão democrática da escola pública não se efetiva no espaço das macro e micropolíticas na atual conjuntura.

Palavras-chave: Democracia. Gestão Democrática. Escola Pública.

\section{THE DEMOCRATIC MANAGEMENT OF THE PUBLIC SCHOOL UNDER THE EGYPT OF NEOLIBERAL CAPITALISM}

\begin{abstract}
The paper aims to discuss the contradictions that are put to the democratic management of the public school in the neoliberal capitalist context, considering that the legislation establishes this principle in C.F of 1988, in LDB $n^{\circ} 9.394$ / 96 and in PNE 2014/2024 Law $13.005 / 2014$. From this perspective, it is based on the assumption that progressive degrees of pedagogical, administrative and financial management autonomy are guaranteed, in accordance with the general rules of public financial law for education

\footnotetext{
${ }^{1}$ Graduação em Estudos Sociais e História pela Universidade Regional do Noroeste do Estado do Rio Grande do Sul (1989- 1993), Graduação em Pedagogia; Pós-graduação em Educação, Cultura e Cidadania pela Unijui; Mestrado em Educação pela Universidade Federal de Santa Maria na linha de Pesquisa Políticas Públicas. Doutorado em Educação pela UFSM linha de pesquisa Práticas Escolares e Políticas Públicas. Experiência na área de Educação, com ênfase em Gestão e na Área de Ciências Humanas como docente da educação básica e ensino superior, atuando principalmente nos seguintes temas: formação inicial e continuada de professores, trabalho e educação, educação do campo, política educacional, gestão democrática. Professora da Universidade Federal de Santa Maria (UFSM) e Universidade Aberta do Curso de Especialização a Distância em Gestão Educacional - Atuação na Facisa/ Celer como professora e orientadora de monografias no Curso de Formação Pedagógica para Docentes da Educação Profissional e na Inter@tiva Consultoria e Assessoria Educacional desde o ano de 2007 até 2013, como professora colaboradora. Consultora da UNESCO, prestando serviço ao Ministério da Educação -MEC, na condição de pesquisadora. Professora adjunta da Universidade Federal do Ceará atuando nos cursos de graduação com a disciplina de Estrutura, Gestão e Política Educacional e professora e pesquisadora da Pósgraduação em Educação Brasileira, na Linha de Pesquisa Trabalho e Educação. E-mail: claricezientarski@yahoo.com.br.
} Brasil (UAB) como bolsista, orientadora de monografias - Programa de Formação de Professores - do
\end{abstract}


professionals, educational communities and educational units. It is a bibliographical and documentary research with a qualitative approach, standing as one of the studies carried out by the GEPPGE / UFC Group. The development of investigations, although partial, in view of the continuity of the measurements, leads to the conclusion that the democratic management of the public school is not effective in the space of macro and micropolitics in the current conjuncture.

Keywords: Democracy. Democratic Management. Public School.

\section{Introdução}

Este trabalho tem como objetivo principal discutir as contradições que estão postas para a gestão democrática da escola pública no contexto neoliberal, considerando que a legislação estabelece este princípio na Constituição Federal de 1988-C. F.-, na Lei de Diretrizes e Bases da Educação Nacional no 9.394/96 - LDB-, e no Plano Nacional de Educação 2014/2024-PNE-, Lei no 13.005/2014.

O estudo situa-se como um dos resultados de pesquisas que está sendo realizado no Estado do Ceará pelo Grupo GEPPGE/UFC- Grupo de Estudos e Pesquisas sobre Politicas, Gestão da Educação e Formação de Professores da Universidade Federal do Ceará $^{2}$. Trata-se de uma discussão fundamentada metodologicamente na pesquisa qualitativa com análise documental e bibliográfica.

Neste sentido, parte da premissa de que a democratização da educação pressupõe a democratização do conhecimento e do acesso, a garantia de permanência e a democratização da gestão. Estas prerrogativas têm sido de maneira geral, as bandeiras levantadas pelos professores brasileiros em suas lutas e movimentos sociais, e, as mesmas reivindicações chegaram a ser formalizadas na Lei, conforme citado no parágrafo anterior, porém, como a Lei por si só não garante os direitos, o poder econômico e político aumentaram seus privilégios e a concepção de democracia fragilizou-se.

\footnotetext{
${ }^{2}$ O GEPPGE/UFC desenvolve estudos e pesquisas vinculado ao Projeto em Rede: Gestão democrática do ensino público: mapeamento das bases normativas e das condições político-institucionais dos sistemas municipais de ensino, coordenado pelo Prof. Dr. Elton Luiz Nardi, que esta sendo realizado desde o ano de 2015, e envolve pesquisadores da Universidade do Oeste de Santa Catarina (Unoesc), Universidade de Passo Fundo (UPF), Universidade Federal de Santa Maria (UFSM), Universidade Estadual do Rio de Janeiro (UERJ), Universidade Federal do Maranhão (UFMA), Universidade Federal do Ceará (UFC), Universidade Federal do Tocantins (UFT) e Universidade Estadual do Piauí (UESPI). Tem por objetivo analisar o quadro normativo e as condições político-institucionais relativos à gestão democrática do ensino público no âmbito dos sistemas municipais de ensino dos Estados de Santa Catarina, Rio Grande do Sul, Rio de Janeiro, Maranhão, Ceará, Tocantins e Piauí.
}

\begin{tabular}{|l|l|l|l|l|}
\hline Q Rovista Dialectus & Ano 4 & n. 10 & Janeiro - Julho 2017 & p. 169-183 \\
\hline
\end{tabular}


A gestão democrática da Educação está amparada na legislação educacional. $\mathrm{O}$ art. n 206 da Constituição Federal, reiterado no art. $3^{\circ}$ da Lei de Diretrizes e Bases da Educação Nacional (Lei $N^{\circ}$ 9.394/96), preconiza a "gestão democrática do ensino público, na forma desta Lei e da legislação dos sistemas de ensino" (inciso VIII do art. $3^{\circ}$ da LDB). $\mathrm{O}$ art. $\mathrm{n}^{\circ} 14$ da LDB trata especificamente da questão, determinando que “os sistemas de ensino definirão as normas da gestão democrática do ensino público na Educação Básica de acordo com as suas peculiaridades, conforme os seguintes princípios: I - participação dos profissionais da Educação na elaboração do projeto pedagógico da escola; II - participação das comunidades escolar e local em conselhos escolares ou equivalentes".

Nesta direção, o art. $\mathrm{n}^{\circ} 17$ da LDB prevê a autonomia da escola para promover uma gestão participativa: “os sistemas de ensino assegurarão às unidades escolares públicas de Educação Básica que os integram progressivos graus de autonomia pedagógica e administrativa e de gestão financeira observada às normas gerais de direito financeiro público". A Lei $n^{\circ}$ 13.005/2014 do PNE referenda o que está definido na Constituição de 1988 e assegura os princípios da democratização da educação, a autonomia e a participação.

Assim, se por um lado, estes marcos legais tornam evidentes esses princípios democráticos, por outro lado, o período em que estes se tornam leis é marcado pela substituição das relações interpessoais pelas que são medidas apenas pela mercadoria, a separação entre trabalho e capital, e a substituição do conhecimento específico pela capacidade de trabalho abstrato (DUARTE, 2001).

Duarte sublinha que:

No influxo da terceira revolução industrial, a ofensiva selvagem do capital recriou o ideal do livre mercado, desenvolveu novas formas de exploração do trabalho humano e pôs em movimento um processo de dessolidarização da vida social, um autêntico salve-se quem puder, expresso no culto do individualismo e naquelas formas relativistas de pensar, que cultivam a fragmentação e a descrença nas possibilidades emancipatórias da razão. Essa nova etapa do capitalismo, marcando a transição do fordismo-keynesianismo para o pós-fordismo e o neoliberalismo exigiu uma reestruturação da produção e consequente precarização das relações de trabalho (DUARTE, p.103. 2001).

\begin{tabular}{|l|l|l|l|l|}
\hline Govista Qialoctus & Ano 4 & n. 10 & Janeiro - Julho 2017 & p. 169-183 \\
\hline
\end{tabular}


Neste contexto, portanto, em que como afirma Wood (, p. 201) na "estrutura conceitual da democracia liberal não se pode falar e nem mesmo pensar em liberdade do mercado" e, ainda, "não se pode pensar em libertação do mercado como uma espécie de autonomia, como a libertação de uma coação, a emancipação da coerção e da dominação", como desenvolver princípios democráticos na escola pública? Escola que tem entre os aspectos basilares da democracia a universalização, mas, que Saviani (2007, p. 159) salienta: "promoveu a socialização dos indivíduos nas formas de convivência próprias da sociedade moderna. Familiarizando-os com os códigos formais, capacitou-os a integrar o processo produtivo".

O pêndulo neste caso afastou-se do centro, isto quer dizer, que em nome da universalização, da democratização a escola passou a formar a classe trabalhadora para o mercado de trabalho, pois,

[...] a educação que a burguesia concebeu e realizou sobre a base do ensino primário comum não passou, nas suas formas mais avançadas, da divisão dos homens em dois grandes campos: aquele das profissões manuais para as quais se requeria uma formação prática limitada à execução de tarefas mais ou menos delimitadas, dispensando-se o domínio dos respectivos fundamentos teóricos; e aquele das profissões intelectuais para as quais se requeria domínio teórico amplo afim de preparar as elites e representantes da classe dirigente para atuar nos diferentes setores da sociedade. (SAVIANI, 2007, p. 159).

Diante desta constatação, evidencia-se uma das grandes contradições que envolvem as categorias democracia, democratização da escola pública e o ideário liberal em sua essência, sendo que no momento histórico atual se apresenta com características novas, ainda mais excludentes: o neoliberalismo, em que:

[...] tem sido frequentes as representações destas formas de (des)sociabilização, que se expressam como se a humanidade tivesse atingido seu ponto alto, o seu télos. Muitas são as formas de fetichização: desde o culto da sociedade democrática, que teria finalmente realizado a utopia do preenchimento, até a crença na desmercantilização da vida societal, no fim das ideologias. Ou ainda aqueles que visualizam uma sociedade comunicacional, capaz de possibilitar uma interação subjetiva, para não falar daqueles que visualizam o fim do trabalho como a

\begin{tabular}{|l|l|l|l|l|}
\hline Q Povista Dialectus & Ano 4 & n. 10 & Janeiro - Julho 2017 & p. 169-183 \\
\hline
\end{tabular}


realização concreta do reino da liberdade, nos marcos da sociedade atual, desde que um pouco mais regulamentada e regida por relações mais contratualistas (ANTUNES,2001, p.35).

O que se verifica é que:

Desconhecer que a sociedade 'em seu conjunto' não é homogênea enquanto for uma sociedade de classes, fragmentada por interesses antagônicos - e que o Estado e o Direito estão a serviço das classes dominantes-, tem levado os trabalhadores a se iludirem com propostas políticas irrealizáveis, que buscam eliminar o caráter de classe do Estado e do Direito e a humanizar o capitalismo (LESSA; TONET, 2008, p.102).

Nesta esteira, deduz-se que a democracia burguesa se alimenta à medida que o modelo utópico (PARO, 2003) que a alimenta funciona como invólucro e simulacro de uma realidade social cujo conteúdo é a desigualdade social. Santos; Andriolli (1999) defendem que, na atualidade, existe a emergência de uma nova contratualidade liberal individualista, construída a partir do direito civil entre os indivíduos e não da ideia de contrato social entre agregações coletivas de interesses sociais divergentes.

As formas de regulação transnacional de mercado, ao final da década de 1980, impulsionaram um quadro de reorganização da lógica capitalista na perspectiva de mudança reestruturativa da produção e do papel do Estado (FRIGOTTO, 2003). Assim, o Estado se coloca como um agente regulador dos meios para a naturalização de seus pressupostos, entre os quais, a educação e o combate à miséria tomam centralidade. Exatamente a partir destes pressupostos é que a democratização da escola pública que foi bandeira dos movimentos sociais populares, do professorado em suas lutas, acaba sendo solapada pelo Estado, que se colocada a serviço da valorização do capital e encaminha para a sociedade civil (haja vista sua natureza contraditória) e empresariado, a responsabilização sobre as politicas públicas e sociais, como, por exemplo, sobre a educação. Este, portanto, é o teor do presente trabalho.

\section{O capitalismo neoliberal, seu ideário e as características que o configuram como um "novo deus".}

Francisco de Oliveira (1990) afirma que como num teatro o mundo se viu diante do neoliberalismo como uma reordenação para a valorização do capital. Caíram muros,

\begin{tabular}{|l|l|l|l|l|}
\hline Q Rovista Dialectus & Ano 4 & n. 10 & Janeiro - Julho 2017 & p. 169-183 \\
\hline
\end{tabular}


damas de ferro governam e mesmo os mais progressistas se renderam a esta onda em que o Brasil também entrou. O mundo especialmente a partir dos anos 1990 é este que, como afirma Oliveira, tem no mercado um novo deus. A resposta dada por este modelo à sociedade revela um grau de concentração de renda de forma nunca antes observada e miséria cada vez maior da população. Ricardo Antunes assinala que o modelo capitalista se sustenta na super-exploração por meio da jornada excessiva, baixos salários e intensidade do trabalho.

Estas características alimentam o projeto capitalista atual assimilando as demandas por mais liberdade individual, e foi construído um novo arcabouço econômico para o mundo em que o Estado não exerceria mais a função distributiva do modelo anterior (Keynesiano). A regulação dos recursos passa a ser feita pelo mercado que, por ser formado por indivíduos livres, racionais e proativos, é mais capaz de alocar os recursos onde eles fossem mais necessários (lucrativos). Nessa perspectiva, os serviços públicos deveriam ser privatizados e os demais recursos, postos a serviço da especulação.

A realidade mostrou a supremacia que o mercado passou a assumir tornando-se, em muitas situações, maior do que a sociedade. Nessa direção, capitais foram utilizados para alavancagens infinitas, criando uma moeda virtual que gerou inflação, ineficiência, desigualdade e desemprego. Trata-se de um fenômeno real, embora complexo, com implicações sócio-políticas e econômicas na sociedade. Com a globalização se verificou a subjugação dos estados nacionais e sua soberania por meio de ações e atores transnacionais (SANTOS; ANDRIOLLI, 1999). Esta é uma das questões que são criticadas, pois, ela evidencia a prepotência e a mundialização do capital e provoca a subjugação. Esse processo envolve o mundo de forma diferenciada e exclui a maior parte dos países e povos.

Diante deste quadro, por um lado, o Estado passou a criar políticas de inserção social para as pessoas excluídas do mundo do trabalho através de políticas compensatórias. E, por outro lado, as políticas estruturais em nome da qualidade, da tecnologia, da modernidade têm colaborado para aumentar o desemprego e a desigualdade social. O Modo de produção capitalista passa por uma grande transformação e o Estado contribui com o seu delineamento, à medida que se torna mínimo, no atendimento das necessidades sociais, e ampliado, no sentido dado por Gramsci, quando quer levar a cabo as reformas.

\begin{tabular}{|l|l|l|l|l|}
\hline Q Ronista Dialectus & Ano 4 & n. 10 & Janeiro - Julho 2017 & p. 169-183 \\
\hline
\end{tabular}




\section{Clarice Zientarski}

Esse delineamento encampado pelo Estado brasileiro a partir da segunda metade da década de 1980 consolida-se nos anos de 1990, quando o ideário neoliberal é incorporado como salvação do crescimento econômico, cadenciando a orientação das políticas públicas. No que diz respeito às politicas públicas a adesão do país ao ideário neoliberal forçou a deixar de lado essas politicas como direito, o caráter universal e gratuito dos serviços e nesse aspecto insere-se a educação e as politicas educacionais.

As políticas educacionais então, sendo projetadas e implantadas segundo as exigências da produção e do mercado, com o predomínio dos interesses dos países ricos, isto é, daqueles que dominam a economia, passam a atender as determinações dos organismos internacionais como, por exemplo, o Fundo Monetário Internacional- FMIe o Banco Mundial - BM (SANTOS; ANDRIOLLI, 1999).

Assim, o discurso passou a ser mais de caráter humanista, especialmente da parte da $\mathrm{UNESCO}^{3}$ e da $\mathrm{UNICEF}^{4}$, como agências ligadas à ONU, correspondendo às exigências de justiça social dos países mais empobrecidos. Dessa forma, estes órgãos assumem a pobreza, estrategicamente, como forma de mostrar para a sociedade que, na perspectiva do neoliberalismo, as políticas educacionais não foram esquecidas. Este discurso, que traz em seu interior princípios como o da equidade e eficiência, revela claramente seu interesse, ou seja, precisa ser eficiente para que haja uma melhor distribuição de renda, como se isso fosse possível e dependesse apenas desse caráter de eficiência.

Além disso, associa-se a estes encaminhamentos uma forte revalorização da privatização e da terceirização como estratégias mais apropriadas para resolver os problemas de eficiência e qualidade nos serviços públicos. Neste sentido, criam-se argumentos para justificar a necessidade de expandir o ensino privado e faz-se uma crítica contundente à escola pública em todos os níveis, mas especialmente na educação básica.

Estes recursos, entretanto, não foram suficientes e era necessário transferir para outros setores a responsabilidade do Estado sobre a educação e para tanto, lança-se mão da própria reivindicação dos movimentos sociais dos professores, estudantes e sociedade que reivindicavam autonomia, descentralização e democratização. O governo, ao "lançar mão do ardil de incorporar, na legislação", algumas das bandeiras do

\footnotetext{
${ }^{3}$ Organização das Nações Unidas para a educação, a ciência e a cultura.

${ }^{4}$ Fundo das Nações Unidas para a Infância.

\begin{tabular}{|l|l|l|l|l|}
\hline Q Rovista Dialectus & Ano 4 & n. 10 & Janeiro - Julho 2017 & p. 169-183 \\
\hline
\end{tabular}
}


movimento dos professores e outros movimentos sociais de caráter popular, consolidadas nos anos de 1980, "ceifou-lhes a fecundidade, adulterou o sentido original de seu conteúdo" (SHIROMA, et al 2002, p.52), portanto, passa para a sociedade o senso comum, a ideia de que foi ela, através dos seus movimentos a responsável pelas mudanças advindas da aprovação da LDB nº 9.394/96 exatamente no período histórico de consolidação do neoliberalismo no Brasil.

Isto, se efetiva á medida que o Estado impelido em garantir a produção e reprodução da sociedade capitalista neoliberal desenvolve toda uma tática de autolegitimação mediante alocução e prática das políticas públicas e das ações populares. A partir disso estabelece-se uma linguagem artificial e sedutora, como afirmam Schiroma, Morais e Evangelista (2002), com o objetivo de envolver os agentes sociais em uma lógica e em uma dinâmica de responsabilidades na realização de tarefas concebidas por tecnocratas à distância, impondo à sociedade a tarefa de resolver seus próprios problemas, realizando ações que caberiam ao Estado. Nesse enfoque, as concepções de autonomia, descentralização, cidadania e democratização apresentam-se como uma falácia, visto que na conjuntura neoliberal:

[...] qualquer tipo de poder social precisa ser cercado pela proteção da liberdade de associação, de comunicação, de diversidade de opiniões, de uma esfera privada inviolável etc. qualquer futura democracia continuara a receber lições sobre esses temas da tradição liberal, tanto na teoria quanto na prática. Mas o liberalismo - até mesmo como ideal, para não falar de sua realidade carregada de imperfeições- não está equipado para enfrentar as realidades do poder numa sociedade capitalista, muito menos para abranger um tipo mais inclusivo de democracia do que o que existe hoje. (WOOD, 2006. p. 204)

Nesta perspectiva, o movimento reivindicatório que lutava por mudanças na educação não conseguiu atingir seus objetivos, porque o governo por meio da legislação - LDB 9394/96- omitiu as responsabilidades cabíveis ao Estado, que "não cerceia o Executivo de pôr em andamento seu próprio projeto político-educativo por outras vias" (SHIROMA, et al2002, p.51). Isto se explica em parte, porque, tais mudanças, decorrentes do processo de descentralização das funções do Estado, proporcionalmente, acabam por repassar um maior compromisso à sociedade e especialmente à comunidade educativa.

\begin{tabular}{|l|l|l|l|l|}
\hline Q Rovista Dialectus & Ano 4 & n. 10 & Janeiro - Julho 2017 & p. 169-183 \\
\hline
\end{tabular}


A gestão democrática das instituições educativas

Dentre os aspectos importantes que dizem respeito à democratização, sem dúvida, a gestão democrática e a autonomia da educação merecem ser discutidos tendo em vista as questões elencadas acima. Cabe salientar, entretanto, que para a democracia existir de fato, seria necessária toda uma transformação não apenas da sociedade, mas a modificação da estrutura vigente, pois com a estratificação social a democracia não tem como existir. Assim, se parece evidente que a gestão democrática por si só não garante o pleno funcionamento da escola nem da sociedade, ela se apresenta como uma possibilidade de democratização da escola, pelo menos nos ambientes em que se desenvolve a prática educativa escolar.

Para Ferreira (1998) a democracia depende da participação, pois ela é um processo de democratização emancipatória na conquista incessante de novos espaços e de novas formas de cidadania individual e coletiva. Nessa ótica, embora sejam questionadas as limitações sobre a gestão democrática, não se pode negar que a legislação fornece, mesmo que burocraticamente, uma possibilidade de descentralização, o que se afirmou a partir da Constituição Federal promulgada no ano de 1988, que instituiu em seu Artigo $1^{\circ}$ o "Estado Democrático de Direito" e, com isto, a participação na esfera pública a todos os brasileiros.

Os artigos nº 205 e 206 da Constituição de 1988 asseguram o direito à educação e à participação por meio da gestão democrática, respectivamente, como princípios do ensino público, em todos os níveis. Nesse prisma, a Constituição institucionalizou, no âmbito federal, práticas recorrentes em vários sistemas de ensino estaduais e municipais.

Nessa direção, a LDB aprovada em 1996, ao afirmar o princípio da gestão democrática instituído com a Constituição Brasileira, conforme salientado anteriormente, dispõe em seu Art. 14 o compromisso dos sistemas de ensino em deliberar sobre as normas de gestão democrática, envolvendo os profissionais da educação na elaboração do projeto político-pedagógico da escola e as comunidades escolar e local em Conselhos Escolares ou equivalentes.

A Lei no 13.005/2014, que institui o Plano Nacional de Educação define como uma das suas diretrizes, no Art. $2^{\circ}$ VI: a promoção do princípio da gestão democrática da educação pública.

Ainda, o Art. 9- estabelece que:

\begin{tabular}{|l|l|l|l|l|}
\hline Q Rovista Dialectus & Ano 4 & n. 10 & Janeiro - Julho 2017 & p. 169-183 \\
\hline
\end{tabular}


[...] os Estados, o Distrito Federal e os Municípios deverão aprovar leis específicas para os seus sistemas de ensino, disciplinando a gestão democrática da educação pública nos respectivos âmbitos de atuação, no prazo de 2 (dois) anos contado da publicação da Lei, adequando, quando for o caso, a legislação local já adotada com essa finalidade. (BRASIL, 2014).

O Plano Nacional de Educação reforça, portanto, a concepção da democratização, quando destaca entre seus objetivos, a elevação do nível de escolaridade da população, melhoria da qualidade e democratização da gestão do ensino público, dentre outros.

A grande dificuldade é que "o sistema escolar na sociedade capitalista tem funções definidas pela estrutura econômica, mediatizada pelo Estado Intervencionista" (FÉLIX, 1986, p.31). Estas funções baseiam-se, principalmente, no modo de produção capitalista, consistindo na preservação da divisão entre trabalho manual e trabalho intelectual, que é a chave do processo de produção de mais-valia e acumulação do capital.

Com efeito, Saviani (2007, p.159) salienta que a divisão dos homens a partir da revolução industrial fundamentou-se em dois grandes campos: aquele das profissões manuais para as quais "se requeria uma formação prática limitada à execução de tarefas mais ou menos delimitadas, dispensando-se o domínio dos respectivos fundamentos teóricos"; e ainda "aquele das profissões intelectuais para as quais se requeria domínio teórico amplo a fim de preparar as elites e representantes da classe dirigente para atuar nos diferentes setores da sociedade”. Não se pode ignorar, nessa esteira, que a democracia burguesa constrói-se sobre a crença de que o indivíduo escolhe livremente, entre aqueles que se apresentam a cada nova eleição, o seu governante, ou seja, uma falsa ideia de democracia, em outras palavras, a democracia burguesa.

Para Mendonça (2011), historicamente o papel da escola é o de transmitir conhecimentos, mas diante das crises que a escola tem sofrido, por conta das mudanças ocorridas na sociedade, esta não mais consegue ensinar e, consequentemente, os estudantes não mais aprendem os conteúdos escolares. Contrapondo esta ideia Warde (1979) reafirma o pensamento de Saviani quando diz que "é só aparente o fato de que a escola não prepara. Sob as perspectivas das relações dominantes, o 'não-preparo' do filho do operário é o seu preparo necessário para que se reproduzam as relações sociais de produção" (WARDE, 1979, p. 61).

\begin{tabular}{|c|c|c|c|c|}
\hline Ronita Dialectus & Ano 4 & n. 10 & Janeiro - Julho 2017 & p. $169-183$ \\
\hline
\end{tabular}


Diante deste quadro, ao trazer novamente o PNE- 2014/2024 pode-se inferir que a administração da educação, bem como a própria instituição escolar, entendida como um conjunto de decisões precisa assumir novas práticas para superar os processos centralizadores, fragmentados, burocráticos que acabam reforçando o controle capitalista sobre a sociedade, o que se manifesta por meio de decisões arbitrárias, fundamentadas nos interesses e concepções alheias aos segmentos sociais que se articulam junto com as escolas. Para tanto é necessário que a:

[...] administração escolar se habilite, dentro de uma visão nova e atualizada do homem e do mundo, seguindo uma filosofia que inspire a superar toda situação que manipula e oprime, e a leve à prática decidida da co-responsabilidade e da colaboração de todos. (FROTA, 1984, p. 25).

Nesse sentido, conforme Paro (2000) é preciso superar a teoria geral da administração que se impõe à teoria da administração da educação, que faz com que os gestores não se compreendam como seres históricos, pois, apresentam-se distantes de suas bases e não percebem a parcialidade de suas práticas, agindo como gerentes do trabalho alheio e suas práxis tornam-se burocratizadas.

Torna-se claro, pois que, mesmo que a legislação traga a gestão democrática como possibilidade da melhoria da qualidade da educação, e os autores e teóricos aqui já citados acreditarem na superação do modo de produção capitalista, o que se efetiva na escola pública, conforme o que foi visto em pesquisas já realizadas pelo Grupo GEPPGE/UFC, é um processo de gestão centralizado que, se utilizando de um discurso democrático presente em seus projetos políticos pedagógicos e no cotidiano da escola apenas contribui com a ordem social vigente.

Para Saviani,

A especialização de tarefas dentro da sociedade, à medida que esta se tornou mais complexa, levou à criação de sistemas de aprendizagem diferenciados. Mas foi sobretudo a cristalização na sociedade da divisão em classes sociais com interesses próprios e antagônicos que consagrou a educação como um dos meios mais eficazes para perenizar, ao longo das gerações, a divisão interna da sociedade. A invenção da escrita não fez senão reforçar os privilégios da minoria que tinha acesso ao saber (SAVIANI, 1996, p. 228).

\begin{tabular}{|l|l|l|l|l|}
\hline Q Rovista Qialectus & Ano 4 & n. 10 & Janeiro - Julho 2017 & p. 169-183 \\
\hline
\end{tabular}


Como se observa, em um modelo e projeto de sociedade que provoca e referenda a divisão em classes sociais, seria necessário que a democracia recuperasse o sentido de governo pelo povo ou poder do povo, conforme defende Ellen Wood, para isso é necessário transformar radicalmente o capitalismo, que é um sistema que reduz gradativamente as esferas da vida social do controle popular e democrático. Esperar que na escola pública, instituição subsumida pelo Estado e pelo modo de produção capitalista de valorização do capital a democracia se efetive é afirmar com Paro a "utopia da gestão democrática".

Nessa linha de raciocínio, a democratização da escola pública implica não apenas no acesso da população a seus serviços, mas também "a participação desta na tomada de decisões que dizem respeito a seus interesses, o que inclui o envolvimento no processo de escolha de seus dirigentes" (PARO, 2003, p. 27), situação que em grande parte do Brasil ainda não se efetiva, por conta das limitações impostas pelo modo de produção capitalista e suas relações.

\section{Considerações finais}

Neste breve estudo intentou-se trazer uma pequena discussão a respeito da gestão democrática da escola pública no modo capitalista de produção e, especialmente no contexto em o neoliberalismo se afirma com um processo de devastação social em nosso país, iniciada com Collor, em 1990, seguido pelos governos subsequentes, que nos legaram um brutal processo de privatização, um vasto movimento de financeirização e um enorme ritmo de precarização social (ANTUNES, 2001.).

Nesta conjuntura, os termos empregados nas empresas, bem como o modelo de gestão empresarial reverberam nas escolas públicas e são incorporados ao cotidiano escolar, visando a atingir os objetivos determinados pelo modo de produção vigente. A instituição escolar, bem como os diversos segmentos que a compõem, é forçada a assimilar métodos, técnicas e determinações que garantam a sustentação do sistema. Para atender a esses pressupostos, termos como clientela em relação aos estudantes, e gestão da educação ou administração da educação em relação á direção, têm sido utilizados na área educacional como sinônimo, ou não, porque a gestão compreendida como processo agregado ao modo de produção coloca na área educacional conceitos de sistemas e gestão escolar e da lógica empresarial.

Neste prisma,

\begin{tabular}{|l|l|l|l|l|}
\hline Q Ronista Dialectus & Ano 4 & n. 10 & Janeiro - Julho 2017 & p. 169-183 \\
\hline
\end{tabular}


Clarice Zientarski

Analisar a gestão da educação, seja ela desenvolvida na escola ou no sistema municipal de ensino, implica em refletir sobre as políticas de educação. Isto porque há uma ligação muito forte entre elas, pois a gestão transforma metas e objetivos educacionais em ações, dando concretude às direções traçadas pelas políticas. (BORDIGNON; GRACINDO, 2004, p.147).

É importante salientar, entretanto, que democratizar a administração da educação não significa eliminar a presença do Estado (neste momento) dos serviços públicos, embora este esteja a atender aos propósitos do capital, mas buscar mecanismos para submeter às decisões do Estado ao debate e ao controle pela opinião pública, pais, profissionais da educação, grupos e partidos.

Isso porque esboça Lenin com relação ao Estado,

A sociedade capitalista, considerava nas suas mais favoráveis condições de desenvolvimento, oferece-nos uma democracia mais ou menos completa na República democrática. Mas, essa democracia é sempre comprimida no quadro estreito da exploração capitalista; no fundo, ela não passa nunca da democracia de uma minoria, das classes possuidoras, dos ricos. A liberdade na sociedade capitalista continua sempre a ser, mais ou menos, o que foi nas repúblicas da Grécia antiga: uma liberdade de senhores fundada na escravidão. Os escravos assalariados de hoje, em consequência da exploração capitalista, vivem por tal forma acabrunhados pelas necessidades e pela miséria, que nem têm para se ocupar de "democracia" ou de "política"; no curso normal e pacífico das coisas, a maioria da população se encontra afastada da vida política social (2007, p.106-107).

O teórico explica ainda,

Só na sociedade comunista, quando a resistência dos capitalistas estiver perfeitamente quebrada, quando os capitalistas tiverem desaparecido e já não houver classes, isto é, quando não houver mais distinções entre os membros da sociedade em relação à produção, só então é que "o Estado deixará de existir e se poderá falar de liberdade". Só então se tornará possível e será realizada uma democracia verdadeiramente completa e cuja regra não sofrerá exceção alguma (idem, p. 109).

Neste sentido, compreende-se a necessidade da superação não só do Estado, mas da sociedade baseada na propriedade privada, na exploração do homem pelo

\begin{tabular}{|l|l|l|l|l|}
\hline Q Revista Dialectus & Ano 4 & n. 10 & Janeiro - Julho 2017 & p. 169-183 \\
\hline
\end{tabular}


homem, na divisão do trabalho manual e intelectual, no trabalho abstrato caracterizando, dessa forma, a necessidade de uma revolução social, uma transformação capaz de modificar na raiz, ou seja, a sociedade civil com sua natureza contraditória.

\section{Referências:}

ANDRIOLI, A. I.; SANTOS, Robinson dos. Educação, globalização e neoliberalismo: o debate precisa continuar!. Revista Iberoamericana de Educación (Online), Internet, 2005.

ANTUNES, Ricardo. Trabalho e precarização numa ordem neoliberal. A cidadania negada: políticas de exclusão na educação e no trabalho. São Paulo: Cortez (2001): 35-48. Disponível em: http://biblioteca.clacso.edu.ar/ar/libros/educacion/antunes.pdf. Acesso dia 02/03/2017, às $11 \mathrm{~h}$.

BORDIGNON, Genuíno. Gestão Democrática do Sistema Municipal de Educação. In: Município e Educação. In: GADOTTI, M. e ROMÃO, J. E. (Org.), Município e Educação. São Paulo, p. 135-171, Cortez, 1993.

BRASIL. Lei $n^{\circ} 13.005$ de 25 junho de 2014. Aprova o Plano Nacional de EducaçãoPNE e dá outras providências. Recuperado em 10 de junho de 2015, de https://www.planalto.gov.br/ccivil_03/_ato2011-2014/2014/lei/113005.htm.

Lei n ${ }^{\circ} 9.394$ de 20 de dezembro de 1996. Lei de Diretrizes e Bases da Educação

Nacional. Recuperado em 30 de março de 2015, de www.planalto.gov.br/ccivil_03/leis/19394.htm.

. Constituição da República Federativa do Brasil de 1988. Brasília. Recuperado em 03 julho 2015, de http://www.planalto.gov.br/ccivil_03/Constituicao/Constituicao.htm.

DUARTE, Newton. Vigotski e o "aprender a aprender": crítica às apropriações neoliberais e pós-modernas da teoria vigotskiana. 2. ed. rev. e ampliada. -

Campinas, SP: Autores Associados, 2001. (Coleção educação contemporânea).

FÉLIX, Maria de Fátima Costa. Administração escolar: um problema educativo ou empresarial? São Paulo, Cortez, Autores Associados, 1984.

FERREIRA, Naura S. Carapeto. Gestão democrática da educação: atuais tendências, novos desafios. São Paulo, Cortez, 1998.

FROTA, Fernando Aguiar. Administração escolar e participativa a serviço da escola atualizada. Ceará, Trabalho do curso de Especialização em Metodologia do Ensino Superior, UVA/ FAFISO, 1984.

LESSA, S. TONET, I. Introdução à filosofia de Marx. São Paulo: Expressão Popular, 2008.

\begin{tabular}{|l|l|l|l|l|}
\hline Q Rovista Dialectus & Ano 4 & n. 10 & Janeiro - Julho 2017 & p. 169-183 \\
\hline
\end{tabular}


MENDONÇA, Sueli G. de Lima. A crise de sentidos e significados na escola: a contribuição do olhar sociológico. Caderno CEDES. v. 31, n. 85, p. 341-357, 2011.

PARO. Vitor Henrique. Administração Escolar Introdução Crítica. 9a ed. São Paulo: Cortez, 2000.

SAVIANI, Dermeval, Trabalho e educação. Revista Brasileira de Educação v. 12 n. 34 jan./abr. 2007. Disponível: https://www.google.com.br/\#q=saviani+escola+p\%C3\%BAblica+para+mercado+de+tra balho\&*. Acesso em: 26/02/2017, às 10h.

SHIROMA, Eneida. MORAES, Oto Maria Célia M. EVANGELISTA. Olinda. Política educacional. Rio de Janeiro: DP\&A, 2002

WARDE, Mirian Jorge. Educação e estrutura social. A profissionalização em questão. São Paulo, Cortez \& Moraes, 1979.

WOOD, Ellen M. Democracia contra o capitalismo a renovação do materialismo histórico. São Paulo. Boitempo. 2003.

\begin{tabular}{|l|l|l|l|l|}
\hline Q Ponista Dialectus & Ano 4 & n. 10 & Janeiro - Julho 2017 & p. 169-183 \\
\hline
\end{tabular}

